\title{
P47 Hypertension Prevalence in Health Sciences Students of the University of Guadalajara
}

Claudia Yanette Galan Ruiz*, David Cardona Müller, Ernesto Germán Cardona Muñoz, Sylvia Elena Totsuka Sutto, Brandon Giovany Illescas Vidrio, Fernando Grover Páez, Carlos Gerardo Ramos Becerra

Universidad De Guadalajara, Centro Universitario de Ciencias de la Salud, Guadalajara, Mexico

\begin{abstract}
Hypertension (HTN) is considered within the first 9 preventable causes of death in Mexico [1]. In order to estimate HTN prevalence in students a blood pressure (BP) measuring campaign was performed at the University of Guadalajara.

Methods: BP was measured in morning shift students, none with known chronic diseases. Before the measurement a survey was made to identify the cardiovascular risk factors, BP was measured in 3 occasions with an automatized sphygmomanometer (OMRON HEM907XL), according to the recommendations and protocol of international guidelines [2]. The average of the measurements were used to classify the subjects in normotensive $(<140 / 90 \mathrm{mmHg})$ and hypertensive $(\geq 140 / 90 \mathrm{mmHg})$.

Results: 881 subjects were included (603 women and 278 men). The hypertension prevalence was $2 \%$. The prevalence was analyzed in subgroups according to the presence of risk factors. Gender, obesity, tobacco use and alcohol consumption were evaluated obtaining the following odds ratio (OR): 6.23 (Confidence interval (CI) 95\%: 2.4-16.11); 2.47 (CI 95\%: 0.69-8.84) 0.78 (CI 95\%: 0.18-3.4); 3.61 (CI 95\%: 1.43-9.09).
\end{abstract}

Conclusion: HTN prevalence in Health Sciences students was 2\%. The factors that conferred the highest risk to present HTN were male gender and weekly alcohol consumption.

\section{REFERENCES}

[1] Campos-Nonato I, Hernández-Barrera L, Pedroza-Tobías A, Medina C, Barquera S. Hypertension in Mexican adults: prevalence, diagnosis and type of treatment. Ensanut MC 2016. Salud Publica Mex 2018;60:233-43.

[2] Williams B, Mancia G, Spiering W, Agabiti Rosei E, Azizi M, Burnier M, et al. 2018 ESC/ESH Guidelines for the management of arterial hypertension: The Task Force for the management of arterial hypertension of the European Society of Cardiology and the European Society of Hypertension. J Hypertens 2018;36:1953-2041. Disponible en: https://journals. lww.com/jhypertension/Fulltext/2018/10000/2018_ESC_ESH_Guidelines_for_the_management_of.2.aspx\#pdf-link.

(C) 2019 Association for Research into Arterial Structure and Physiology. Publishing services by Atlantis Press International B.V. This is an open access article distributed under the CC BY-NC 4.0 license (http://creativecommons.org/licenses/by-nc/4.0/). 